\title{
LOS PROCESOS DE DIFUSIÓN URBANA EN CANTABRIA
}

\author{
Carmen DELGADO VIÑAS \\ Departamento de Geografia, Urbanismo y Ordenación del Territorio. \\ Universidad de Cantabria
}

Los espacios rurales de Cantabria, tanto los situados en las periferias de las principales ciudades como los que se encuentran más alejados de ellas pero disfrutan de buena accesibilidad, están experimentando desde mediados de la década de los ochenta intensos cambios vinculados a los procesos de difusión de los fenómenos urbanos sobre el territorio: crecimiento de su población, ampliación del parque de viviendas principales y secundarias para uso de población neorrural y urbana e implantación de nuevas actividades privativas del espacio urbano consolidado hasta hace poco. De este modo, aquí también está teniendo lugar el doble proceso, de integración territorial y de dispersión espacial de actividades y población, al que algunos autores han calificado de construcción de la ciudad difusa, ciudad dispersa o città sconfinata (INDOVINA, 1990, LONGO, 1992, SERNINI, 1996). Un proceso que hay que entender no como la producción de otro modelo de ciudad, sino como una nueva etapa en el proceso de urbanización (CHESHIRE, 1995), la postindustrial, a partir de la cual "cada pueblo y cada rincón rural del mundo capitalista avanzado (se están convirtiendo) en parte de una compleja telaraña de urbanización que desafía toda categorización simple de la población entre 'urbana'y 'rural' en el sentido que antaño podía darse razonablemente a estos términos" (HARVEY, 1996, 38).

En sentido estricto no puede afirmarse que este fenómeno sea absolutamente novedoso en Cantabria; existen antecedentes de difusión de algunos usos urbanos en el medio rural en torno a las principales ciudades, Torrelavega y Santander sobre todo (DELGADO y GARCíA MERINO, 1995). Pero aquel proceso, que quizá haya que calificar de "suburbanización sin expansión de la ciudad" (DEMATTEIS, 1998), fue muy diferente del actual tanto en intensidad como en amplitud. Las desemejanzas no parecen ser sólo cuantitativas; el cambio de escala también conlleva disimilitudes cualitativas territoriales en relación con la mejora de la movilidad personal y en proporción al rango y tamaño de los espacios urbanos inductores y al dinamismo económico del conjunto territorial (DELGADO, 1998).

\section{EL INICIO DE LOS CAMBIOS EN LAS FORMAS DE DISTRI- BUCIÓN DE LA POBLACIÓN SOBRE EL TERRITORIO.}

Para entender lo que está pasando conviene tomar como referencia la dinámica poblacional anterior a los años ochenta y sus efectos sobre la distribución de la po-

Polígonos, no 9, 1999, pp. 71-96. 
blación regional, muy desequilibrada ya desde mediados de siglo y concentrada principalmente en el área central septentrional, entre Santander y Los Corrales de Buelna, y en unos pocos municipios del litoral oriental.

El crecimiento demográfico de la década de los cincuenta consolidó esa distribución ya que la mayor parte de los municipios que experimentaron un incremento superior al $10 \%$ se encuentran en aquella comarca, si bien participan todavía del crecimiento municipios algo más alejados de la capital, con valores proporcionales a la distancia de ésta. Lo mismo puede afirmarse para el área Torrelavega-Los Corrales de Buelna.

Esta forma de crecimiento, muy concentrada, se prolonga de manera aún más acusada en la década siguiente: sólo 10 municipios crecen por encima del 10\%, todos ellos urbanos y suburbanos, pero, a diferencia de la etapa anterior, casi todos los espacios rurales de lo que luego serán las coronas periurbanas pierden ahora buena parte de su población. La evolución demográfica de la década de los setenta sigue las mismas pautas sin apenas diferencia, salvo la incorporación a los valores positivos más altos de algunos municipios próximos a Torrelavega (Polanco), Santander (Medio Cudeyo) y Reinosa (Campoo de Enmedio), y la villa lebaniega de Potes.

Se cubre así, en Cantabria, la fase definitiva de crecimiento urbano y suburbano (JAILLET, 1982, JALABERT, 1986 y KLAASEN, 1981), con valores máximos en Santander y los municipios colindantes (El Astillero y Camargo), en el área Torrelavega-Los Corrales y en la pequeña aglomeración de la desembocadura del Asón formada por las ciudades de Laredo y Santoña y el municipio suburbano de Colindres. Por el contrario, las tres cuartas partes de los municipios de la provincia perdieran población, a veces en unas proporciones tan pavorosas que algunos términos de las comarcas de Alto Campoo, Tudanca, y Miera llegaron casi a despoblarse.

Los primeros cambios significativos en esta forma de crecimiento empiezan a producirse en el período 1981-1991: se modera el aumento poblacional de los municipios urbanos y suburbanos (sólo Colindres continúa teniendo un crecimiento importante, aunque inferior al de las décadas anteriores) al tiempo que los mayores incrementos empiezan a corresponder a los municipios periurbanos de Santander (Santa Cruz de Bezana, 44,6\%, y Ribamontán al Mar, 24,5\%), a los municipios litorales con mayor desarrollo turístico (Noja y Argoños) y a algunos en los que se ubican villas que refuerzan su funcionalidad urbana como cabeceras comarcales (Cabezón de la Sal, Selaya).

Pero la transformación fundamental corresponde a la década actual: entre 1991 y 1998 los mayores incrementos han correspondido a los municipios de las áreas periurbanas de Santander y, en menor medida, de Torrelavega y de SantoñaLaredo. Resulta significativo, asimismo, que se haya iniciado el des censo de la población de los núcleos urbanos centrales (Santander pierde el 6,1\% de su población. Torrelavega 3,4\% y Reinosa 9,3\%). Las únicas, y elocuentes, excepciones son las pequeñas ciudades de Castro Urdiales, que ha aumentado su población oficialmente en $23,7 \%$, Santoña, $6,7 \%$ y Laredo, $1 \%$. También es revelador el hecho de que haya comenzado a frenarse el decrecimiento de la población rural (no han perdido población "nada más" que la mitad de los municipios de la 
Figura 1: Evolución del crecimiento demográfico

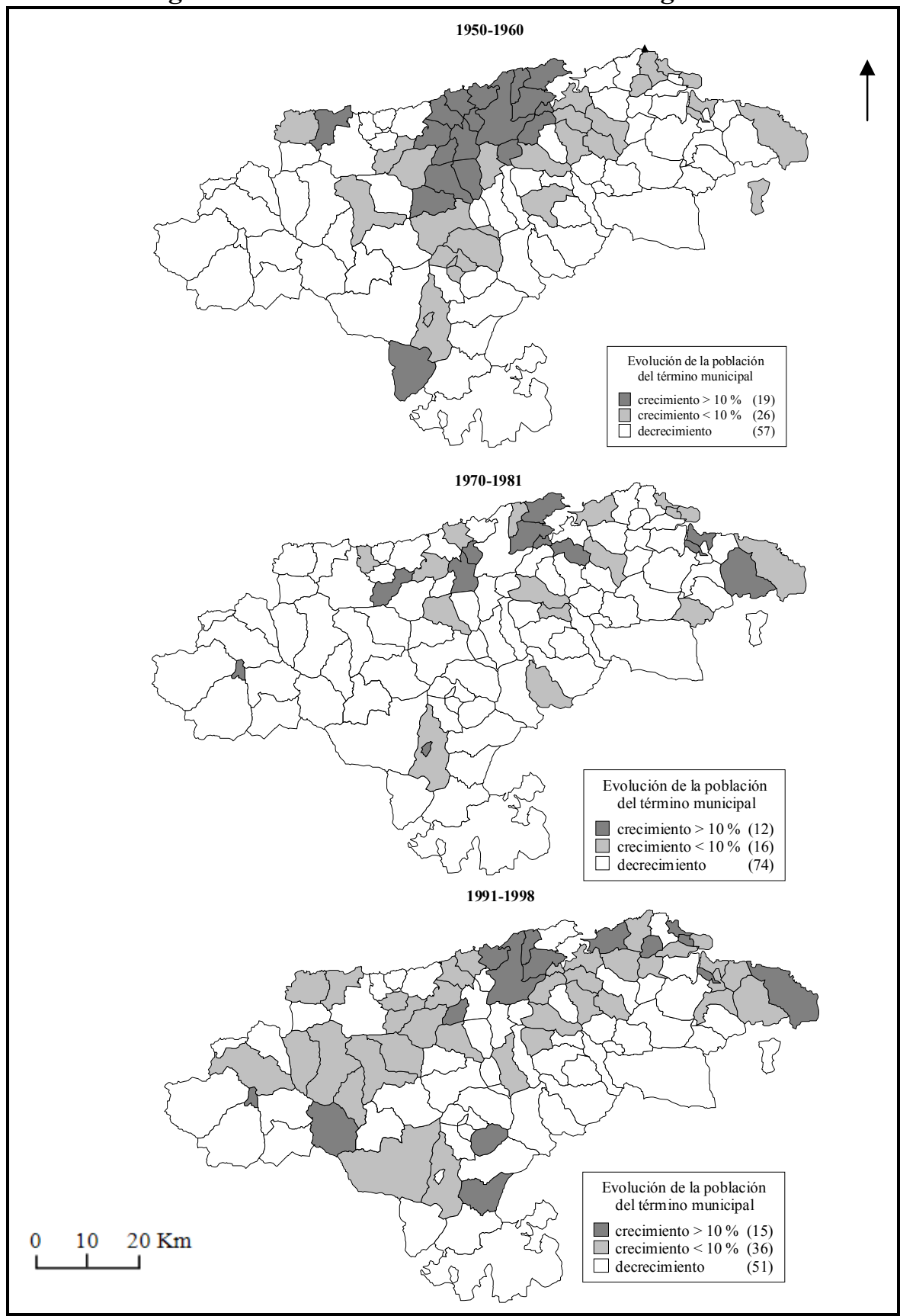

Fuentes: Censos y Padrones de Población. Elaboración propia. 
región), y algunos de los que experimentaron mayores pérdidas en la fase anterior han tenido un pequeño crecimiento en valores absolutos, aunque el incremento porcentual sea muy alto dada la exigüidad de su población.

En cuanto a la forma de crecimiento, es evidente que, como en otros ámbitos, se ha realizado por inmigración, casi siempre desde otros municipios de la región, como pone de manifiesto la clasificación de la población de acuerdo con el lugar de nacimiento: los municipios rurales que han experimentado alguna forma de urbanización presentan los valores más altos, con más del $50 \%$ de sus habitantes nacidos en otros, frente a los valores más bajos correspondientes a los municipios donde la ruralidad es mayor y a los valores medios de los municipios urbanos propiamente dichos.

Pese a su innegable significado como indicadores de una alteración en la dinámica poblacional, los cambios reseñados no han supuesto mutaciones sustanciales en la distribución de la población regional por razones de duración y de intensidad de los procesos (DELGADO, 1997). Por un lado, el período de concentración de la población en los espacios urbano-industriales ha sido mucho más largo mientras que la dinámica actual apenas supera una década. Por otro, el vaciamiento del campo y la acumulación de población en los núcleos urbanos alcanzó valores muy altos, a causa de la propia pujanza del éxodo rural y por su coincidencia con la fase de mayor crecimiento vegetativo, mientras que los valores de la "desurbanización" en el presente son cifras muy modestas, salvo algunas excepciones, entre otras razones porque el proceso actual está teniendo lugar en un contexto de crecimiento vegetativo débil, incluso negativo, tanto en los espacios urbanos emisores como en algunos de los rurales receptores.

Sí se perciben, no obstante, algunos matices diferenciales que deben de ser resaltados. En primer lugar, la consolidación de las aglomeraciones urbanas de Santander, Torrelavega y Santoña-Laredo; después, la modificación de la estructura interna de estas tres áreas urbanas en dos sentidos: el aumento del peso relativo de los núcleos periféricos frente al central en el conjunto de cada área y, en el ámbito de cada municipio, el reforzamiento de una entidad principal que va acumulando un porcentaje cada vez mayor de la población municipal. Se trata de un proceso de redistribución con dos aspectos convergentes y simultáneos, de desconcentración y de centralización según la escala a que analicemos el fenómeno (NAREDO, 1994). Los hechos son absolutamente nítidos si observamos los niveles de concentración de la población en diferentes momentos.

Así, si en 1950 la población habitante en el núcleo principal no llegaba al 30\% en la mayoría de los municipios del área rururbana considerada, en 1998 en casi todos ellos se concentra la mitad de la población en su núcleo mayor y en algunos, incluso, se rebasa esa cifra.

Este hecho se debe al carácter, muy selectivo y discriminado, de la evolución demográfica reciente, como resulta evidente si consideramos individualmente las entidades de población de cada municipio, una escala de análisis absolutamente ineludible en nuestra región habida cuenta del tipo de poblamiento sobre el que se realiza el proceso. Algunos ejemplos ilustran con gran claridad los acusados contrastes que definen la dinámica de la última década. 
Figura 2: Evolución de la distribución de la población regional

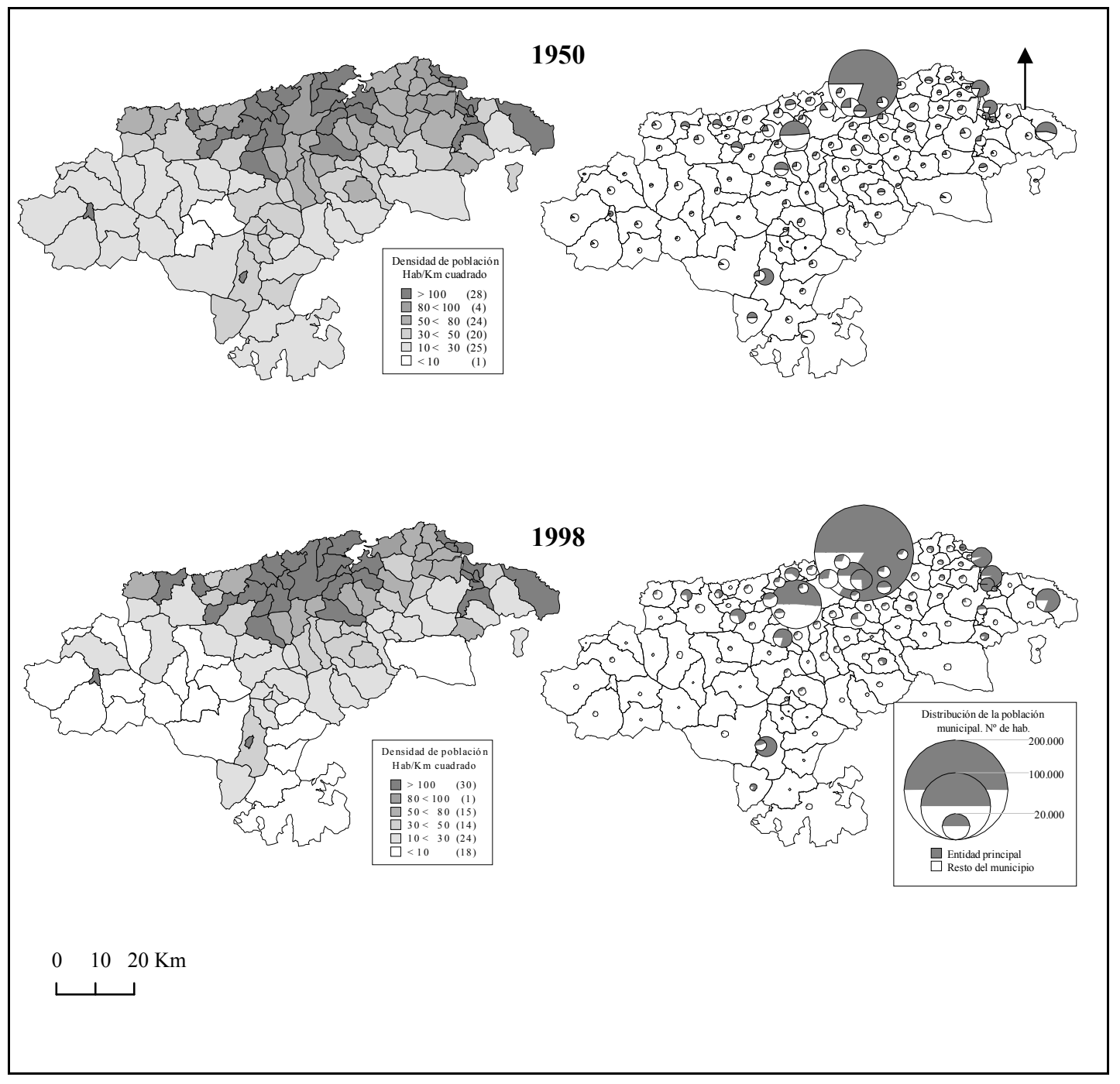

Fuentes: Censo y Padrones de Población. Elaboración propia. 
El crecimiento total del término de Piélagos, en el área periurbana de Santander, ha sido $16,1 \%$ entre 1991 y 1998, una media que esconde situaciones tan dispares como la del pueblo de Mortera, cuyos efectivos demográficos han aumentado $150 \%$, y las de otros núcleos del mismo término (Carandia, Quijano, Zurita) que han perdido población en el mismo plazo. Lo mismo que ha ocurrido en el municipio periurbano de Santander de mayor crecimiento demográfico, Santa Cruz de Bezana (37,1\% entre 1991 y 1998): el pueblo de San Cibrian ha visto incrementada su población en $97,7 \%$ y el de Soto de la Marina en 44,2\%, mientras que otras entidades no han ganado nada o, incluso, han tenido pérdidas (Mompía). El municipio de Cartes, en el área de Torrelavega, es un caso similar: la población municipal ha crecido $33,4 \%$ en los siete años referidos, pero, mientras un núcleo, Santiago de Cartes, lo hacía en $102 \%$, varias aldeas próximas han decrecido.

El proceso de redistribución no sólo es perceptible en los municipios periurbanos sino, también, en los propios municipios urbanos cuando, como sucede en Santander, la ciudad no es la única entidad del término: el núcleo central pierde población pero los otros, antiguos núcleos rurales que funcionan hoy como núcleos suburbanos y periurbanos, la incrementan. En el término de Torrelavega sucede lo mismo: en tanto que el núcleo principal perdía el $1,4 \%$ de sus habitantes, Tanos los aumentaba en $31 \%$.

En realidad, lo que se está produciendo hasta ahora es una redistribución de efectivos demográficos dentro de las áreas urbanas y rurales urbanizadas, un proceso de difusión que, en realidad, prolonga, con matices diferenciales, el proceso de urbanización previo y que, de momento, no parece avanzar hacia una masiva "desurbanización". Por esa razón, también parece claro que la desconcentración demográfica no está siendo el aspecto esencial de los procesos de dispersión urbana, aunque sí está teniendo efectos importantes en la modificación de la trama de asentamientos y de algunos de los rasgos biológicos de la población, en particular en su composición por edades. En un contexto regional de población muy envejecida, destaca por su mayor juventud la de los espacios rurales urbanizados: en 1996 únicamente un municipio suburbano, Colindres, tenía un índice de juventud que superaba el valor 3, pero la mayoría de los municipios periurbanos y rururbanos estaban por encima de 2, o al menos de 1,5. La explicación es clara: la mayor parte de la población que se ha establecido recientemente en estos espacios son adultos jóvenes en edad reproductiva, entre ellos muchas parejas con hijos menores.

\section{LA INGENTE AMPLIACIÓN DEL PARQUE DE VIVIENDAS PARA USO DE LA POBLACIÓN URBANA.}

A pesar de la moderada emisión de población urbana hacia los espacios rurales, los procesos de difusión alcanzan un significado más cabal cuando los observamos desde la perspectiva de la dispersión espacial del hábitat. No es sorprendente, por tanto, que algunos autores utilicen el vocablo rururbanización para referirse de forma restringida a "la fijación en las áreas rurales de viviendas permanentes y de residencias secundarias de urbanos" (BAUER y ROUX, 1976), de modo que esos espacios rurales aparecen hoy sembrados de nuevas construcciones, aisladas o 
en "urbanizaciones", ocupadas por urbanos que permanecen vinculados a la ciudad laboral y socialmente. Esta "invasión" de usos residenciales urbanos es la que está teniendo en Cantabria mayores efectos territoriales, geográficos en definitiva, ya que rompe la organización espacial tradicional del medio rural, en particular el sistema de asentamientos.

Antes de nada, es preciso resaltar que en esta región apenas se ha modificado la dinámica de crecimiento del parque de viviendas en un sentido cuantitativo ya que casi no se ha dejado sentir el proceso general de debilitamiento del crecimiento inmobiliario a partir de los años ochenta. Así, tras el "boom" inmobiliario de los sesenta, se ha mantenido un ritmo muy importante de crecimiento del parque residencial en las tres décadas siguientes. En la última, y a pesar del "bache" que se produjo entre 1992 y 1995, puede hablarse de una nueva fase de apogeo constructivo con visos de continuar en el futuro inmediato ya que se espera que "el volumen actual continuará en la misma línea durante el próximo semestre, e incluso, hasta el año 2000 o 2001" de acuerdo con la información proporcionada por el Colegio de Arquitectos de Cantabria (Diario Montañés, 17/08/1999).

Se observan, sin embargo, diferencias muy significativas en cuanto a la localización de las nuevas viviendas construidas; disparidades que nos permiten afirmar que, también en este aspecto, ha terminado la fase de crecimiento inmobiliario casi exclusivamente urbano y suburbano y se ha entrado en una fase de "estallido de las ciudades", de crecimiento inmobiliario de las pequeñas ciudades más alejadas y, más allá de las periferias suburbanas, de espacios rurales urbanizados y ocupados por las viviendas primarias de población neorrural y por las viviendas secundarias de población urbana (NEL LO, 1998).

Desde mediados de siglo hasta 1980 más de la mitad de las viviendas edificadas de nueva planta fueron construidas en las dos ciudades mayores, Santander y Torrelavega; el porcentaje disminuyó mucho en los años ochenta (38\%), a la vez que se producía la paulatina incorporación a la dinámica de crecimiento inmobiliario de otros espacios; primero los municipios suburbanos de Santander (El Astillero y Camargo) y las pequeñas ciudades de Laredo, Castro Urdiales, Santoña y Reinosa, y, algo más tarde, algunos municipios del litoral con una extraordinaria pujanza de la construcción de viviendas utilizadas como residencias secundarias (Ribamontán al Mar, Noja, Argoños). En el decenio 1981-1991 los municipios en que el parque de viviendas tuvo un crecimiento relativo más destacado correspondieron ya a esos espacios turísticos y a un municipio periurbano de Santander, Santa Cruz de Bezana.

Pero el cambio fundamental se ha producido en el actual decenio, en el que el porcentaje de viviendas construidas en las dos ciudades principales se ha reducido a un exiguo $16,2 \%$, de manera que el volumen de viviendas de nueva planta, en valores absolutos, es mayor en Castro Urdiales y Noja que en Santander, al tiempo que Torrelavega es aventajada, o casi igualada, por los municipios periurbanos y suburbanos de Santander (Piélagos y Camargo). En conjunto, el crecimiento del parque de viviendas de todas las ciudades cántabras entre 1990 y 1999, con la sola y elocuente excepción de Castro Urdiales, se ha mantenido en porcentajes muy bajos (Torrelavega 12\%, Reinosa 9,8\%, Santander 7,4\%, Laredo 5,1\%), mientras que dos municipios del área periurbana de Santander, Santa Cruz de Bezana 
Figura 3: La construcción de viviendas en Cantabria

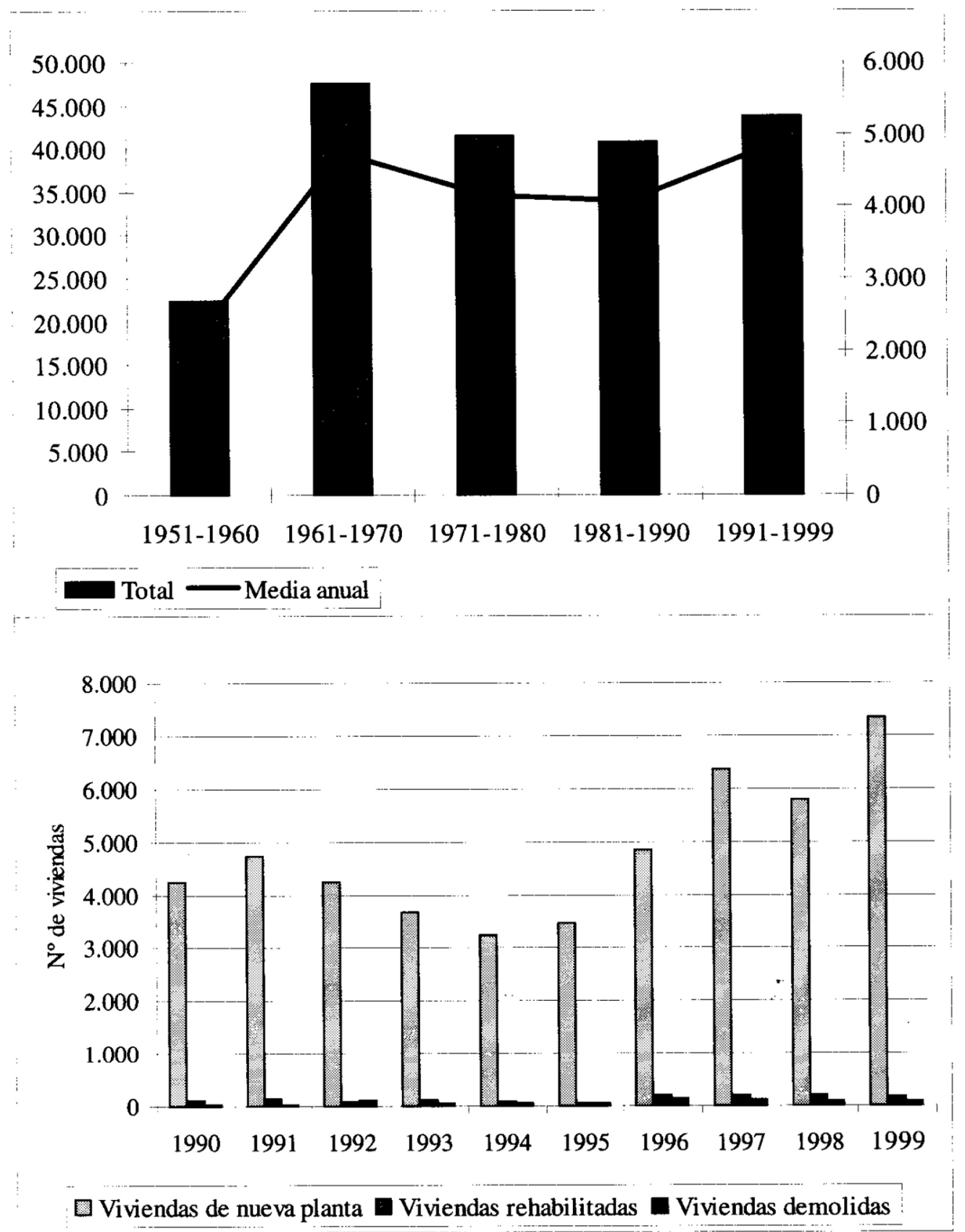

Fuente: Censos de Vivienda y Estadística de Edificación y Vivienda. Elaboración propia 
Figura 4: Distribución de las viviendas construidas de nueva planta

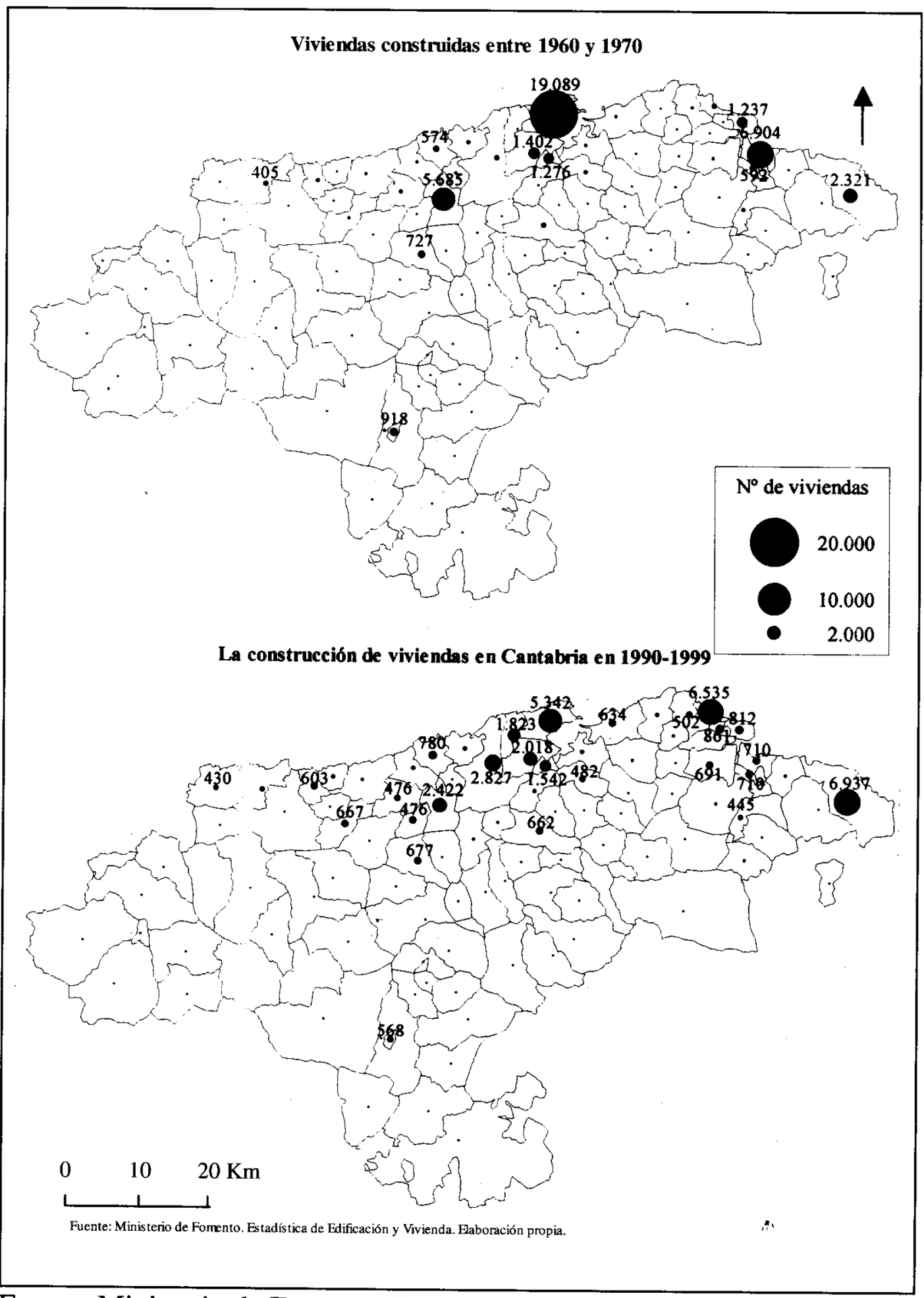

Fuente: Ministerio de Fomento. Estadística de Edificación y Vivienda. Elaboración propia. 
Figura 5: Incremento del número de viviendas familiares

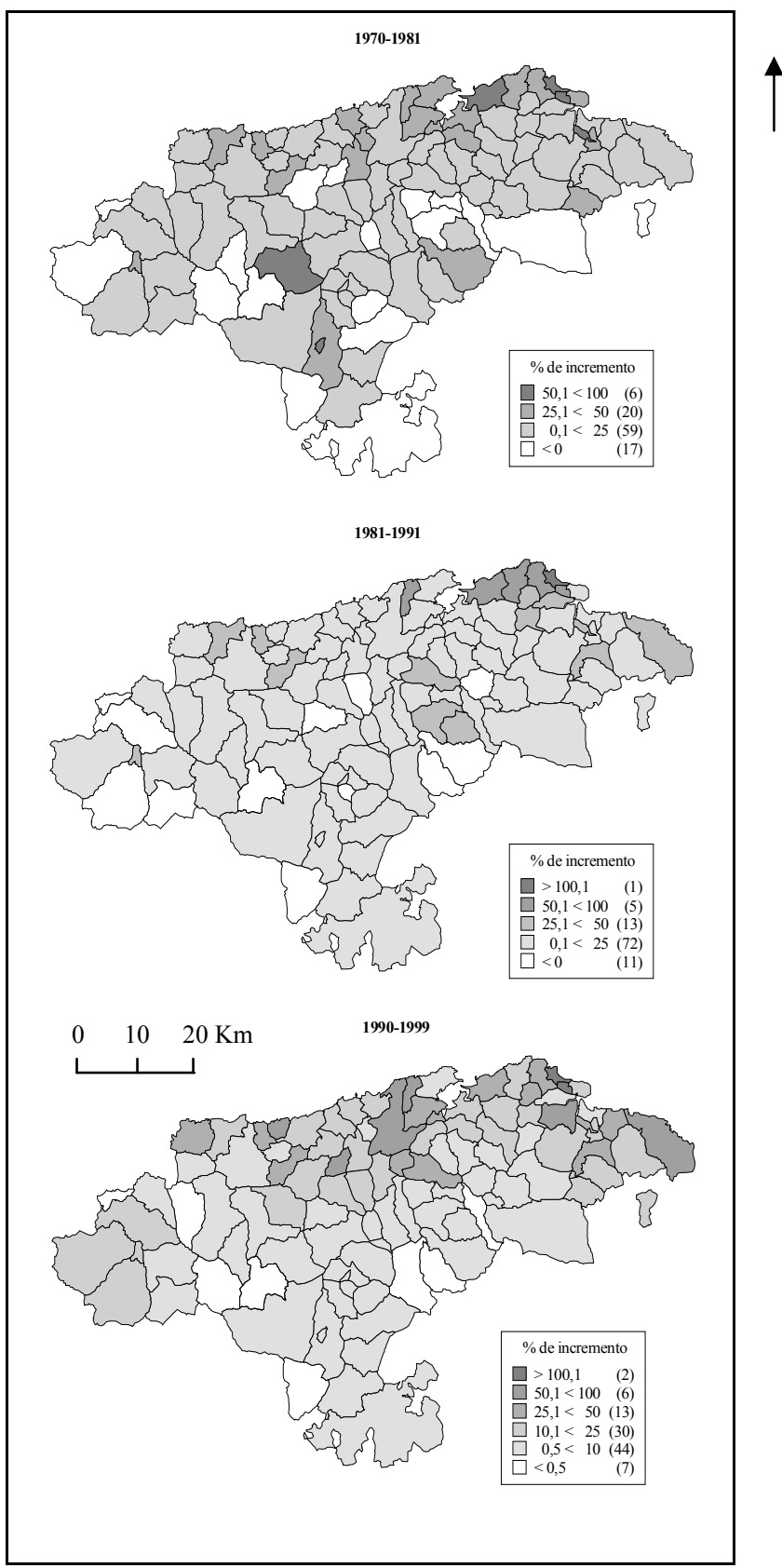

Fuentes: Censos de Viviendas y Estadística de Edificación y Vivienda. Elaboración propia. 


\section{Figura 6: Formas de uso de las viviendas en 1991}

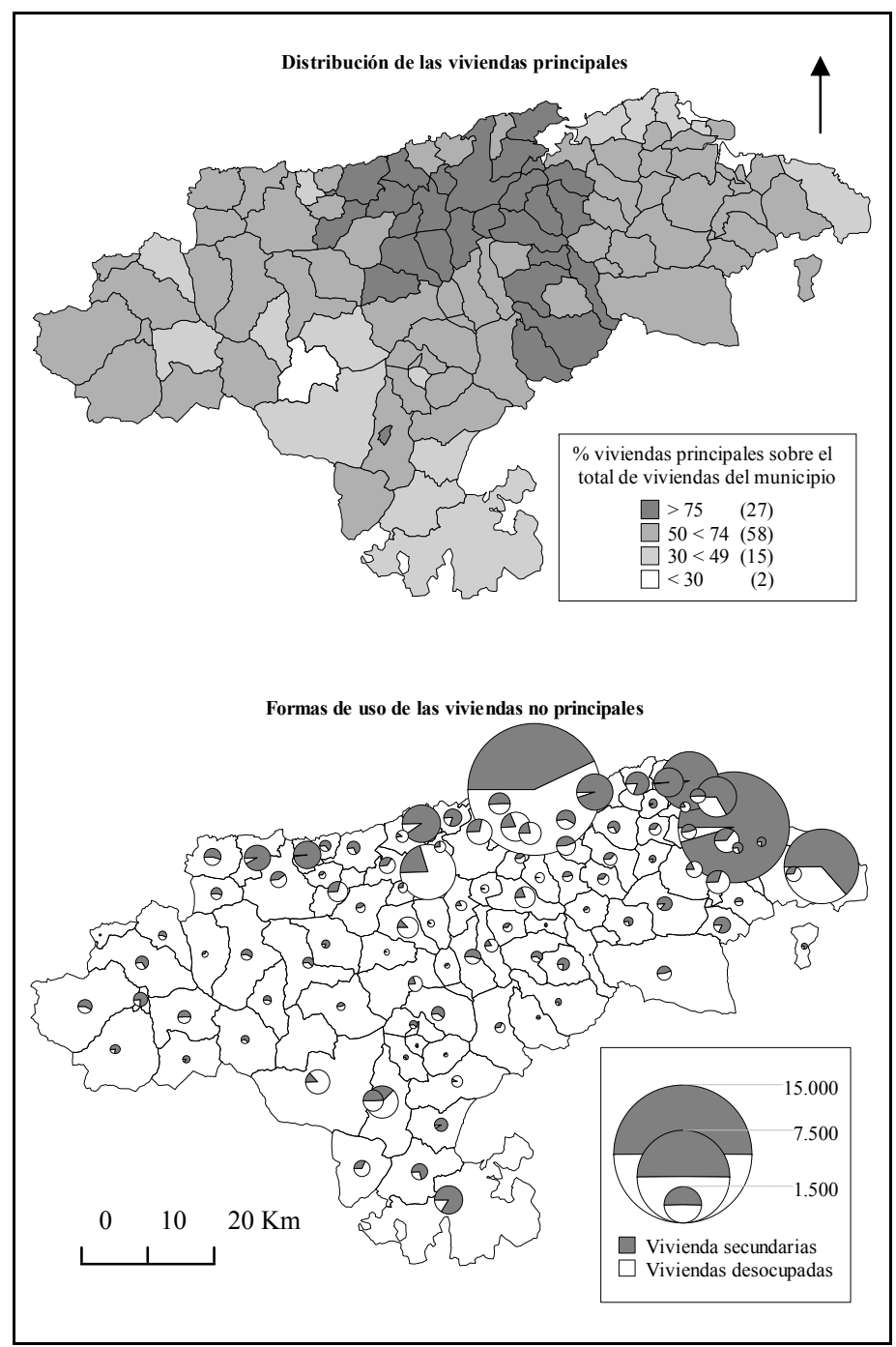

Fuente: Censo de Edificios y Viviendas. Elaboración propia 
(94,5\%) y Piélagos (84,7\%), uno de la de Torrelavega, Cartes $(91,8 \%)$, y otros dos de gran desarrollo turístico, Noja (169,4\%) y Argoños (164,5\%) alcanzan los porcentajes más elevados.

Para completar el análisis hay que hacer referencia a las viviendas rehabilitadas puesto que también incrementan el volumen del parque residencial en uso. Sin embargo, en Cantabria los valores alcanzados son ínfimos (1.394 viviendas rehabilitadas entre 1990 y 1999 frente a 47.951 de nueva planta). La rehabilitación de viviendas está siendo, por otro lado, un fenómeno esencialmente urbano, de ahí que los valores más altos correspondan a Santander, Torrelavega y Castro Urdiales $\mathrm{y}$, bastante por detrás, algunos municipios suburbanos y periurbanos (Suances, Santa Cruz de Bezana, Camargo y Piélagos). Sin embargo, la exigüidad del núme ro de viviendas rehabilitadas no introduce modificaciones significativas en la dinámica reseñada antes a partir de la consideración de las viviendas de nueva planta.

Cabría preguntarse si esta nueva forma de distribución del crecimiento del parque residencial responde a la dinámica reciente del crecimiento demográfico expuesta antes; la respuesta exige muchos matices. En un elevado número de municipios, crecimiento demográfico y crecimiento residencial se han producido de forma simultánea, pero no paralela puesto que los porcentajes de aumento de viviendas son muy superiores a los de aumento de población, salvo contadas excepciones. Más nutrido aún es el número de municipios en que se produce crecimiento del parque inmobiliario sin que haya un aumento significativo de la población o, incluso, con importante decrecimiento de ésta.

Los casos con mayores diferencias corresponden a espacios rurales del litoral oriental (Bárcena de Cicero, Arnuero) y, sobre todo, occidental (Ruiloba, Comillas), en los que la mayor parte de las viviendas de nueva planta se destinan a un uso temporal y discontinuo por parte de habitantes de ciudades de la propia región o de otras próximas; pero, elocuentemente, en la misma situación se encuentra el municipio capitalino con un aumento de $7,4 \%$ en su parque de viviendas y un decrecimiento de $6,1 \%$ en su población.

La relación entre evolución demográfica y evolución inmobiliaria hace obligado tomar en consideración las formas de uso de las nuevas viviendas por parte de sus propietarios y, a partir de ella, hacer una reflexión sobre las distintas formas de difusión residencial urbana sobre los espacios rurales y los diferentes procesos de urbanización del campo.

En este sentido, en Cantabria parecen estar produciéndose dos situaciones diferentes. Por un lado, en la mayor parte de los municipios periurbanos de Santander y Torrelavega el predominio absoluto corresponde a las viviendas permanentes, calificadas en el censo como viviendas principales, con valores siempre superiores al $75 \%$ del parque inmobiliario residencial. La única excepción la constituyen cuatro municipios litorales en los que el porcentaje de viviendas no principales alcanza cifras significativas, aunque tampoco muy elevadas: Suances, Miengo, Santa Cruz de Bezana y Marina de Cudeyo. Por el contrario, las proporciones se invierten en los espacios urbanos y rururbanos del litoral oriental en la mayor parte de cuyos municipios las viviendas no principales representan más de la mitad del parque residencial, siendo los valores más altos los de Noja (88\%) y Laredo (73\%). Sólo en 
Santoña y en los municipios que funcionan como espacio periurbano en la pequeña aglomeración (Colindres, Bárcena de Cicero), tienen predominio las viviendas principales.

Las diferencias en cuanto a modo de utilización del parque de viviendas se perciben con mayor claridad si se consideran las formas de uso de las viviendas no principales. Con las salvedades ya apuntadas de Suances y Miengo, donde las viviendas utilizadas como residencia secundaria son más de las tres cuartas partes de las viviendas no principales, en esta área la mayor parte de las viviendas no principales son viviendas desocupadas, probablemente a la espera de un comprador o un inquilino. En los municipios litorales del sector oriental, ya sean urbanos o rururbanos, así como en algunos del litoral occidental de la región, el predominio entre las viviendas no principales corresponde a las utilizadas como residencia secundaria. Sólo en algunos espacios urbanos y suburbanos (Santoña, Castro Urdiales y Colindres) los valores son algo más bajos. Un hecho que se repite también en algunos espacios rurales de las comarcas montañosas interiores (Liébana, Cabuérniga-Tudanca, Campoo, Pas-Asón).

La interpretación expuesta resulta avalada por la tipología edificatoria dominante. Tomando como indicador el número medio de viviendas por edificio de nueva planta construido durante el período 1990-1999, se observa que en los espacios urbanos el predominio sigue correspondiendo a la vivienda colectiva en bloques: Castro Urdiales, Santoña y Santander superan la media de 10 viviendas por edificio; pero es una tipología constructiva también dominante en los espacios suburbanos y periurbanos (Colindres, Cartes) e, incluso, de los rurales urbanizados para uso residencial turístico (Noja da la cifra más alta, 21,5 viviendas por edificio). En un valor inmediatamente inferior se encuentran muchos otros municipios, urbanos y suburbanos y aquéllos que cuentan con la presencia de villas con rasgos funcionales urbanos, pero también espacios rurales afectados por procesos de periurbanización y de urbanización turística. Lo que denota que esta tipología edificatoria, hasta hace poco esencialmente urbana, se ha generalizado a todo el territorio que experimenta cualquier forma de urbanización. Si bien, a diferencia del modelo constructivo de las décadas anteriores, se han reducido las dimensiones de los bloques en altura y volumen edificado, se ha incorporado la edificación de viviendas adosadas en hileras y ha aumentado la calidad constructiva, tanto en los materiales utilizados como en los aspectos estéticos.

Aunque los bloques de vivienda plurifamiliar empiezan a formar parte del paisaje de la mayor parte de los espacios rururbanos propiamente dichos, al menos en los núcleos de población mayores, en estas áreas el predominio corresponde a las tramas de vivienda unifamiliar, bien sea totalmente independientes, aisladas, o agrupadas en "urbanizaciones", exentas y pareadas. Es lo que hace que en la mayoría de los municipios comprendidos en estos espacios los valores medios se mantengan en 2/4 viviendas por edificio, incluso por debajo de ese valor en otros más alejados del foco urbano principal.

Ahora bien, frente al predominio mayor que, hasta hace poco, estaba teniendo la vivienda unifamiliar, las últimas tendencias parecen confirmar la expansión creciente de la vivienda colectiva, en bloque o en hilera: de las viviendas de nueva planta que se construyeron en Cantabria en el primer semestre de 1999, algo más 
Figura 7: Tipología edificatoria de las viviendas de nueva planta construidas en 1990-1999

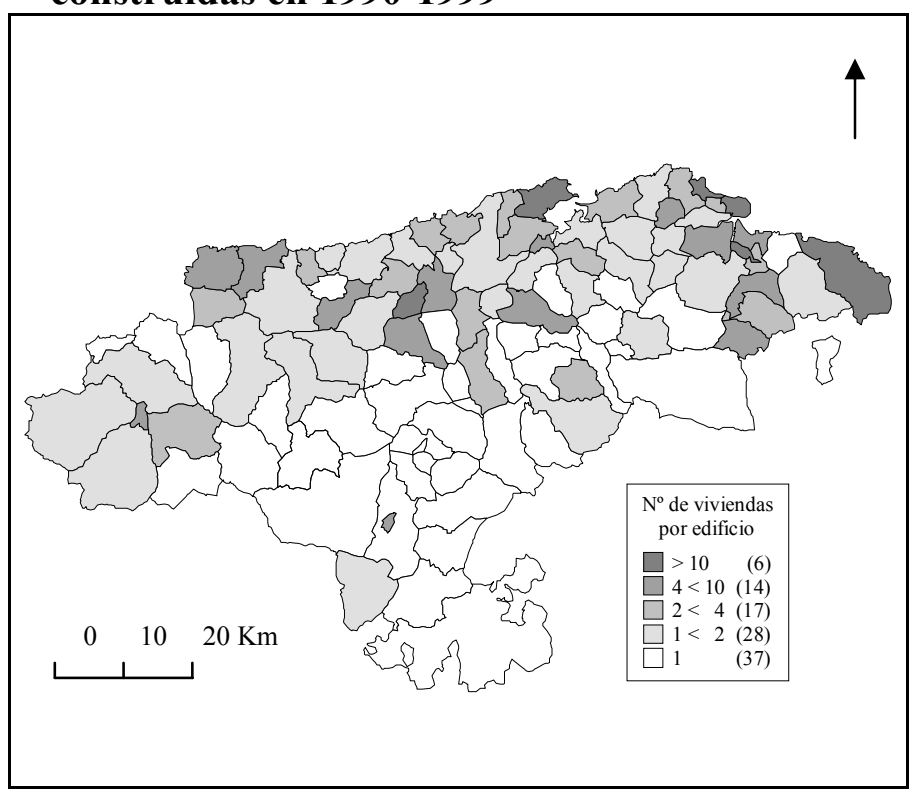

Fuente: Ministerio de Fomento. Estadística de Edificación y Vivienda. Elaboración propia.

Figura 8: El suelo edificado en 1990-1999

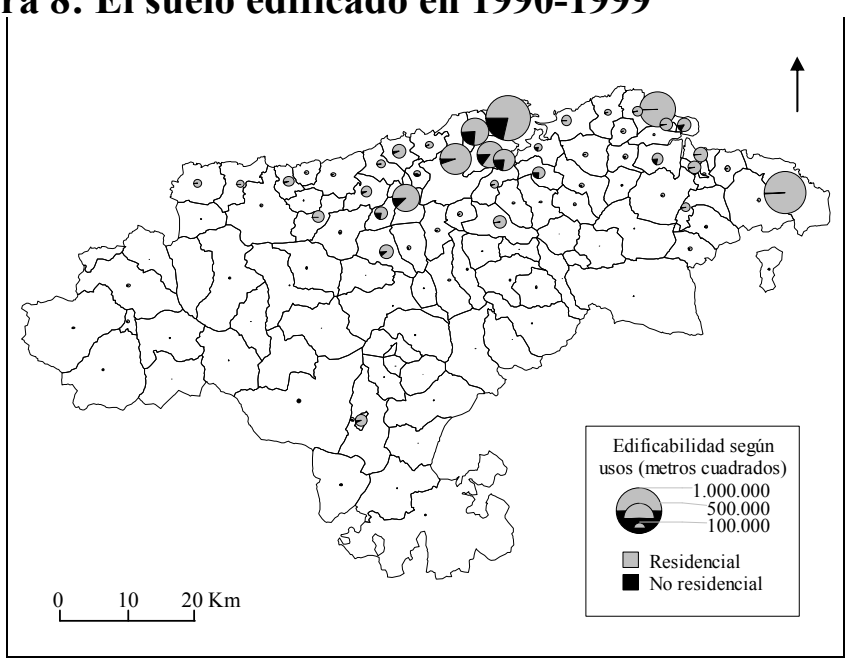

Fuente: Ministerio de Fomento. Estadística de Edificación y Vivienda. Elaboración propia 
del $92 \%$ fueron colectivas (32\% más que el año anterior) mientras que sólo se tramitaron 358 visados, $8 \%$ más que en 1998, para viviendas unifamiliares (Diario Montañés, 17/08/1999).

Las causas parecen estar claras: si en los primeros momentos del proceso de difusión residencial uno de los factores de mayor incidencia fueron los nuevos hábitos de consumo, que estimulaban la demanda de vivienda individual permanente, y más aún de residencias secundarias, como muestra de ascenso social y prestigio, de unos años a esta parte, y cada vez en mayor medida, el factor fundamental es la elevación de los precios de la vivienda urbana y la demanda de viviendas económicas, pero de aceptable calidad, en las zonas periféricas de la capital cántabra, "como Maliaño (Camargo), Bezana o El Astillero", entre otras, en las que resulta "más fácil y más barato conseguir un solar" según el secretario del Colegio de Arquitectos Técnicos (Diario Montañés, 17/08/1999). Los motivos son similares en el caso de la vivienda turística: la socialización de la segunda residencia se ha traducido en la ampliación de la demanda de pequeños apartamentos, asequibles para clases sociales con poder adquisitivo medio, en núcleos costeros hasta ahora poco afectados.

En cualquier caso, las dos tipologías edificatorias dominantes no dejan de tener un gran impacto paisajístico. Impacto en el aspecto morfológico porque, aun cuando predomina la vivienda unifamiliar, se está produciendo una densificación del espacio edificado sin parangón con la situación anterior; en el peor de los casos, la presencia de bloques de vivienda plurifamiliar produce una alteración excesiva de la tipología constructiva tradicional. En el aspecto territorial se debe tener en cuenta el extraordinario consumo de suelo para uso residencial que están teniendo estas promociones de baja densidad. Sólo en la década de los noventa, de 1990 a 1999, los edificios construidos de nueva planta para uso residencial en Cantabria han consumido $6.783 .560 \mathrm{~m}^{2}$. La cifra podría parecer poco elevada por tratarse del conjunto regional, pero no puede olvidarse que el $60 \%$ de ese suelo corresponde únicamente a ocho municipios en cada uno de los cuales se edificaron más de $200.000 \mathrm{~m}^{2}$; en los tres primeros puestos, junto a Santander, se encuentran dos municipios del litoral, Castro Urdiales $\left(860.226 \mathrm{~m}^{2}\right)$ y Noja $\left(651.701 \mathrm{~m}^{2}\right)$.

El uso residencial es, precisamente, el mayor consumidor de suelo: casi el cien por cien en los espacios urbanos y rururbanos con mayor especialización turística, tanto del litoral oriental como del occidental, y en un porcentaje también muy elevado, casi siempre superior al $75 \%$, en los espacios suburbanos y periurbanos del área de Santander y Torrelavega. La construcción de edificios destinados a otros usos lucrativos, que también se están difundiendo desde las ciudades a los espacios rurales, ocupa una superficie mucho menor.

\section{LA RECIENTE IMPLANTACIÓN DE NUEVAS ACTIVIDADES ECONÓMICAS.}

Tal vez el aspecto de la difusión urbana que más ha tardado en producirse ha sido la descentralización productiva, si hacemos salvedad de la precoz salida de algunas industrias a las áreas suburbanas de las mayores ciudades cántabras.

Cuando se toma como indicador la distribución de las licencias de actividades empresariales y profesionales se observa que todavía existe una gran concentración 
del tejido productivo en los espacios urbanos consolidados, con destacado predominio de la capital. Sin embargo, como en otras regiones norteñas (RODRÍGUEZ, 1997), empieza a resultar significativo el número de licencias para actividades no agrarias de que disponen los municipios de las áreas periurbanas de Santander y Torrelavega y, en menor medida, los rururbanos del litoral, así como aquellos en los que se ubica alguna de las villas/cabeceras comarcales con funcionalidad urbana. Pero desde la perspectiva de la distribución por sectores, lo que más destaca es el extraordinario peso que han adquirido las actividades de servicios, un rasgo que es común hoy a todos los espacios de una región en la que el 80,6\% de las licencias disponibles en 1996 corresponde al sector terciario. Por eso es obligado resaltar la presencia más nutrida de estas actividades en los espacios rurales periurbanos, incorporados así al proceso de terciarización de la economía y de la sociedad, uno de los rasgos más expresivos de la modernidad en estos momentos. Es un hecho que no cabe considerar nada más que como otro síntoma de las nuevas formas de urbanización ya que viene a significar la ruptura de la dinámica vinculada a la anterior fase de urbanización, consistente en la disminución de la actividad terciaria en el campo al tiempo que se concentraba en las ciudades casi con exclusividad.

Se perciben, sin embargo, expresivas diferencias locacionales en cuanto a los distintos tipos de actividades de servicios. El número de licencias comerciales es mucho mayor en los municipios periurbanos y en las villas que funcionan como centros de comarcas agrarias. Los servicios de hostelería de frecuentación más continua (cafeterías y restaurantes) e inducidos por el ocio de proximidad, aunque con gran implantación también en estos espacios, empiezan a adquirir un peso desproporcionado a su tamaño demográfico en los espacios rururbanos del litoral con predominio de los usos turísticos. Por esta razón, las instalaciones hoteleras, muy escasas en los espacios periurbanos excepto en los costeros con doble funcionalidad, se concentran de forma masiva en los espacios de urbanización turística del litoral, sobre todo del sector oriental. Por el contrario, resulta elocuente la distribución de las oficinas bancarias: concentradas en los espacios urbanos y rurales urbanizados de la región, se distribuyen dentro de este área de una forma relativamente homogénea, sin que se perciban contrastes significativos entre los espacios periurbanos y los rururbanos turísticos.

La industria ha sido la actividad productiva que inició antes su difusión a los espacios rurales de la periferia urbana, con una importante localización en el área suburbana. Aunque el predominio de esta localización se mantiene en la actualidad, no deja de ser revelador el aumento del número de empresas industriales en los municipios periurbanos, en polígonos industriales o en localización aislada, tanto del área de Santander, como de Torrelavega y, en menor medida, de Santoña-Laredo.

Otra actividad productiva con una gran implantación en los espacios rurales urbanizados, tanto periurbanos como rururbanos turísticos, es la construcción, lo que resulta lógico habida cuenta de la mayor actividad edificatoria que está teniendo lugar en estos espacios. Así, aunque el mayor volumen de licencias corresponde indiscutiblemente a Santander, con 1.070, el segundo lugar lo ostenta un municipio del área periurbana de Torrelavega, Reocín, con un número de licencias, 366, 
Figura 9: Distribución de licencias de actividades empresariales no agrarias en 1996

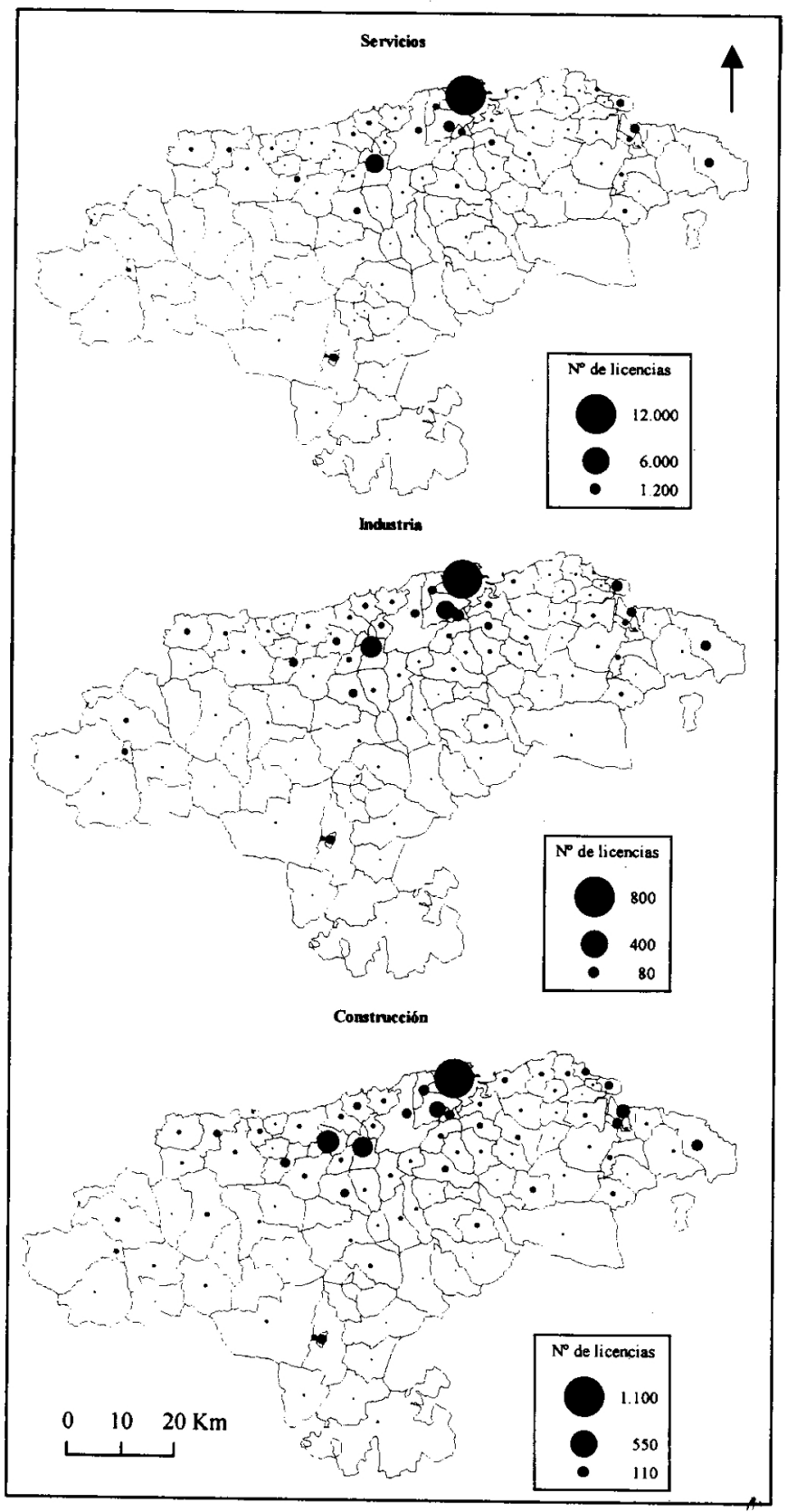

Fuente: Indicadores Estadísticos Municipales. Elaboración propia. 
superior al del municipio central del área. El número de empresas constructoras instaladas en el espacio periurbano de Santander es también muy elevado y su presencia es frecuente, asimismo, en los espacios rururbanos litorales, en particular en la Marina oriental.

Sin embargo, el tipo de empresas con mayor tendencia a concentrarse en los espacios periurbanos, aunque su número sea mucho más pequeño que el de las mencionadas antes, es el de las agrarias; pero se trata de formas de explotación más intensivas, sin tierras en muchos casos, que las practicadas en los espacios rurales propiamente dichos, de los que están prácticamente ausentes.

La reciente afluencia de actividades productivas no agrarias hacia los espacios rurales urbanizados ha producido una importante diversificación profesional, de modo que estos espacios se definen hoy por una nueva estructura socioprofesional marcada por el peso de los empleos secundarios y, sobre todo, terciarios.

No obstante, el proceso de diversificación laboral de la población de estos espacios no es totalmente nuevo. En el conjunto de municipios que configuran hoy las áreas periurbanas de Santander, Torrelavega y Santoña-Laredo-Castro Urdiales ha sido muy importante, desde hace varias décadas, el peso de la población activa no agraria; pero no ocurría lo mismo en los espacios turísticos del litoral. El predominio, en 1980, correspondía en los primeros a la población activa industrial, con valores comprendidos en la mayoría de los casos entre el $40 \%$ y el $60 \%$, mientras que en los segundos, salvo escasas excepciones, apenas se llegaba al 20\%. También se debe destacar la importante presencia que tenía ya la población ocupada en los servicios, aunque siempre por debajo del $40 \%$ con las salvedades de Bezana y Medio Cudeyo en el caso de los municipios periurbanos; tampoco en los rurales del litoral se alcanzaban valores altos, excepto en Comillas. Por el contrario, el peso de la población activa agraria era todavía importante en la mayoría de los casos.

A lo largo de la década de los ochenta tuvieron lugar importantes cambios:

- Una substancial disminución de la población activa agraria en todos los espacios considerados, en particular en los turísticos del litoral, con retrocesos de entre el $10 \%$ y el $20 \%$, incluso superiores en algunos casos. La disminución relativa ha sido menor en los espacios periurbanos, pero debe tenerse en cuenta que se partía, también, de valores más bajos.

- Un decrecimiento generalizado de la población activa industrial en los espacios suburbanos y periurbanos, con pérdidas también de entre $10 \%$ y $20 \%$, mayores en el área de Torrelavega y menores en la de Santander. Al revés, el porcentaje de población activa industrial se ha incrementado en los espacios rururbanos del litoral, en proporciones muy significativas en algunos casos (Meruelo y Escalante).

- Un elocuente aumento del porcentaje de la población ocupada en la construcción, con valores muy heterogéneos salvo en el área rururbana del litoral oriental donde los incrementos son superiores al $10 \%$ en seis municipios.

- Un considerable ascenso de la población ocupada en los servicios en todos los espacios rurales afectados por cualquier forma de urbanización con pequeñas 
Figura 8: $\quad$ Peso relativo de la población ocupada por sectores de actividad en 1991.

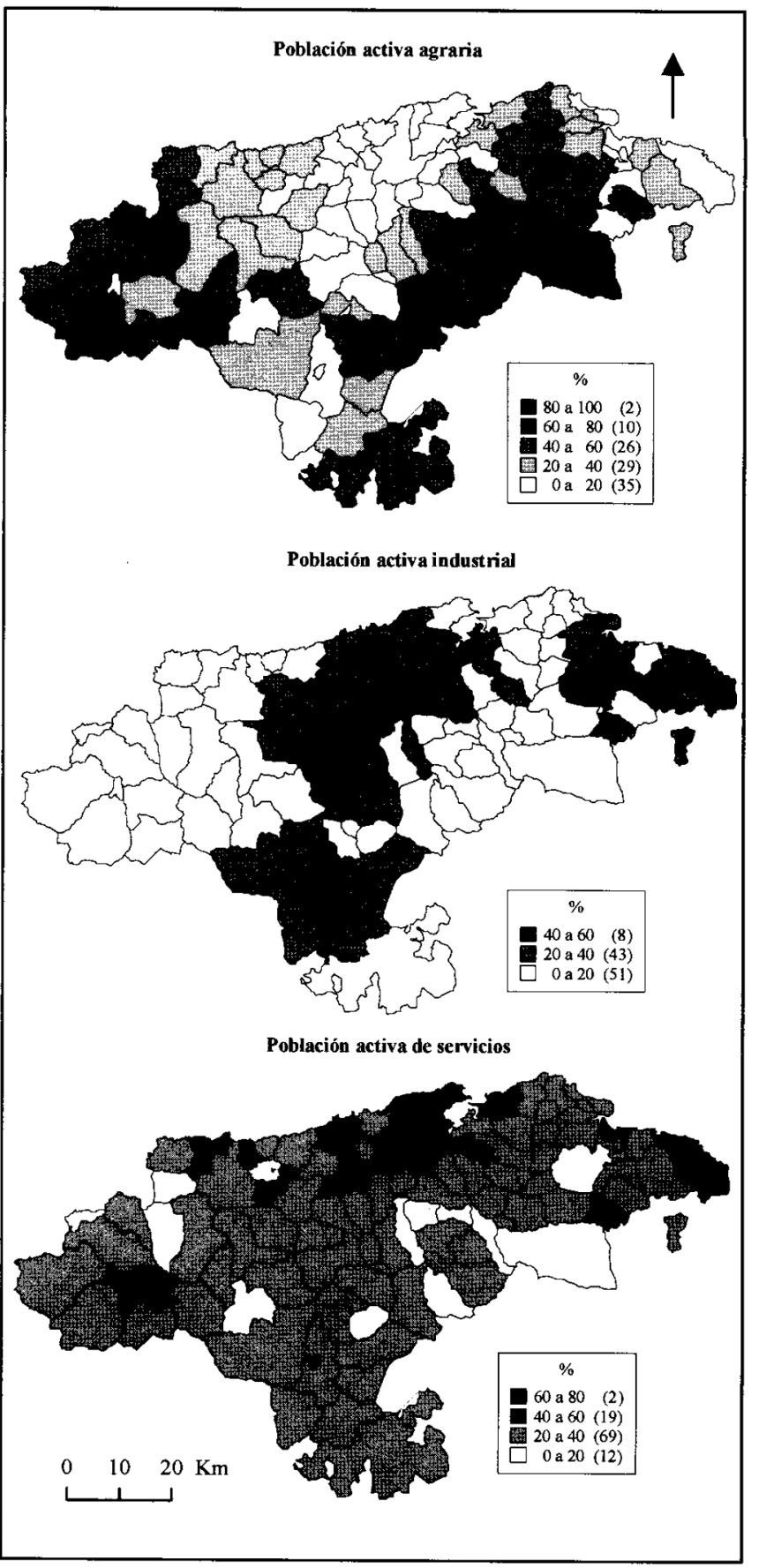

Fuente: 
Figura 11: La construcción de edificios destinados a usos no residenciales en 1990-1999

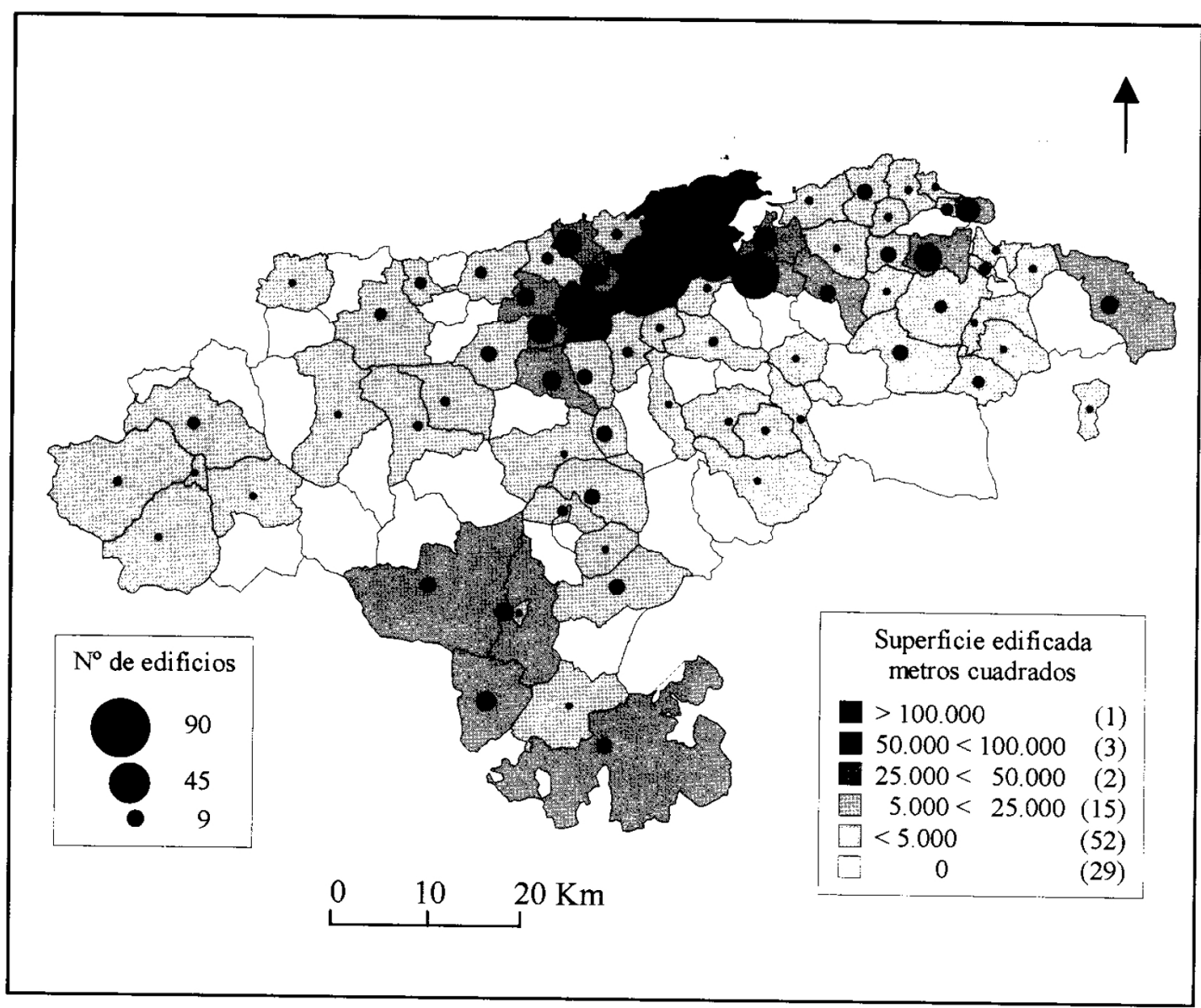

Fuentes: Ministerio de Fomento. Estadística de Edificación y Vivienda. Elaboración propia. 


\section{Figura 12: Niveles de motorización en 1996}

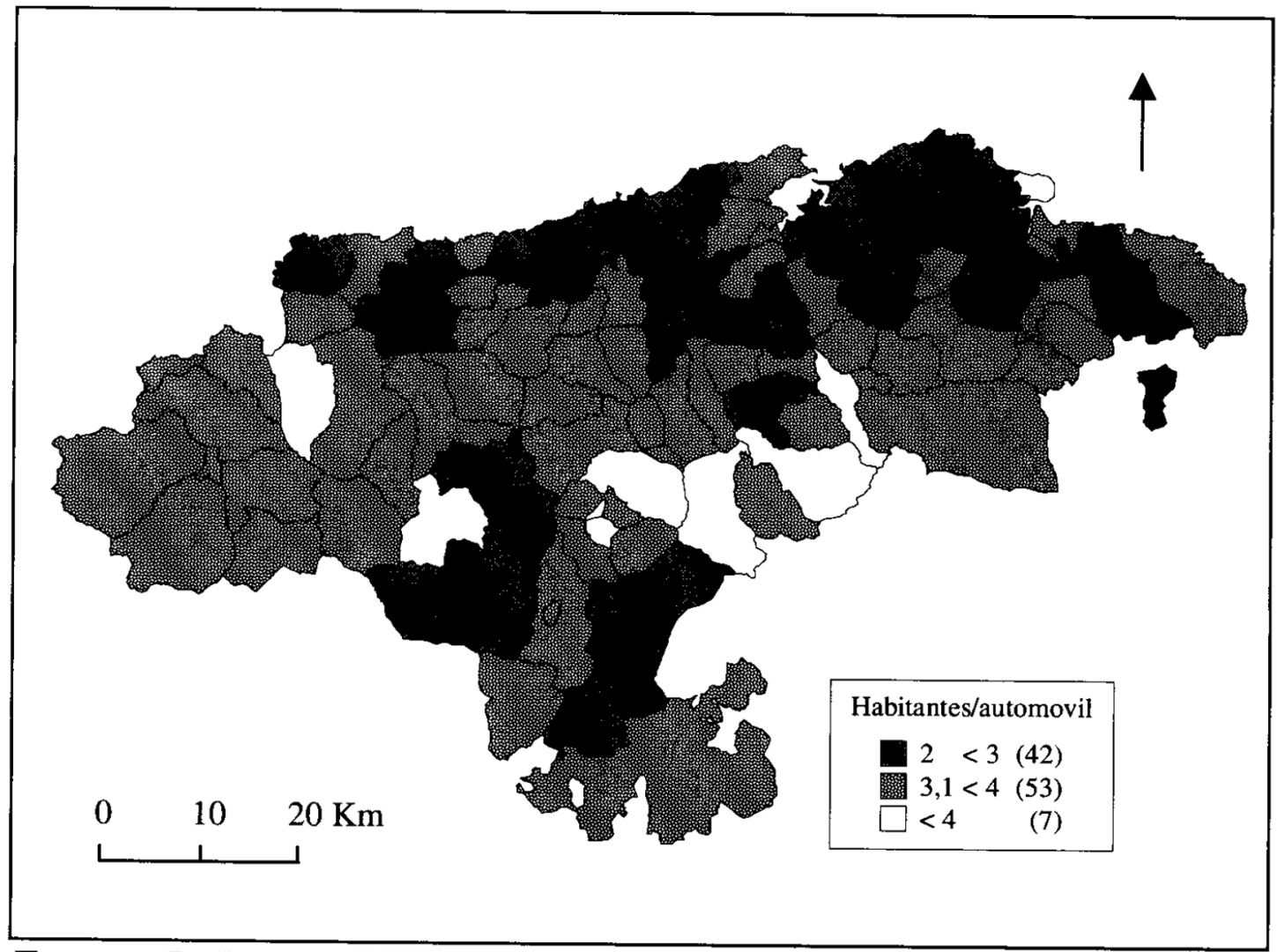

Fuentes: Indicadores Estadísticos Municipales. Elaboración propia. 
diferencias entre unos y otros en cuanto a los incrementos relativos, que permanecen entre $10 \%$ y $20 \%$ en la mayoría de los casos. Otro hecho destacable es que ese aumento ha sido mayor en los espacios periurbanos y rururbanos que en los urbanos consolidados (los incrementos en todas las ciudades son inferiores a 10\%).

El resultado último es la modificación, si no sustancial sí muy importante, de la composición de la población activa. Sin excepciones, aunque con algunas diferencias de matiz, la población activa de los espacios rurales urbanizados de Cantabria era ya a comienzos del actual decenio una población laboralmente diversificada y con una ocupación preferente en el sector servicios; el segundo lugar lo ocupaba la industria en los espacios periurbanos y la actividad agraria en los espacios rururbanos del litoral. En cualquier caso, el modo de vida en estos espacios ha perdido cualquier identificación con la actividad agraria, que pervive como una ocupación productiva más o menos importante pero sin ser nunca la base económica de estos territorios, ni mucho menos el factor determinante en su evolución presente o futura.

Aunque no se disponga de datos de empleo desagregados a escala municipal más recientes, es más que probable que la dinámica expuesta haya proseguido a tenor de la proliferación de equipamientos (centros comerciales, educacionales, sanitarios, servicios de hostelería, etc.) demandantes de empleos terciarios que se siguen instalando al amparo de la urbanización permanente en los espacios periurbanos y, en menor medida, del auge turístico en los rururbanos del litoral. Un hecho que se manifiesta, entre otros síntomas, en el aumento reciente de la construcción de edificios destinados a usos no residenciales.

Sin embargo, la capacidad de empleo propia de muchos de los núcleos de estos espacios no es suficiente para atender la demanda de trabajo de toda su población por lo que buena parte de ella está hoy formada, sobre todo, por migrantes que habitan en el campo y trabajan en alguna de las ciudades próximas o en otro municipio rururbano distinto del de residencia. La generalización de este modo de vida ha sido facilitada por la mejora de los accesos urbanos periféricos y de la red viaria en general, sobre todo a partir de la construcción de varios tramos de la autovía del Cantábrico, en particular el trecho de Bilbao a Santander, y la terminación de la autovía Santander-Bezana-Torrelavega (GARCÍA MERINO, 1996). A lo largo de estas vías, que han dotado a las áreas rurales próximas de mejores condiciones relativas de accesibilidad, se están formando verdaderos "corredores de urbanización"; como probablemente sucederá de inmediato en el tramo de Torrelavega a Cabezón de la Sal inaugurado más tarde ("urbanismo de las obras públicas"). Es por ello que los espacios rurales urbanizados se están convirtiendo en los nuevos "territorios del automóvil" (DUPUY, 1995) como evidencian las tasas de motorización, más elevadas en los espacios rururbanos que en los suburbanos e, incluso, que en los urbanos propiamente dichos.

Como ocurrió diez o quince años antes en otros ámbitos más avanzados, entre los espacios urbanos consolidados y los rurales profundos se está configurando en 
Cantabria un espacio híbrido, de rasgos ambiguos y límites cambiantes, en el que el proceso de urbanización avanza con formas distintas.

Por un lado, en los espacios rurales situados en la periferia de las ciudades mayores, Santander y Torrelavega, se está produciendo un proceso que cabe calificar de periurbanización en sentido estricto, entendida como difusión de funciones desde un polo urbano al área rural más próxima. Sobre todo la función residencial, desempeñada a partir de un nuevo y voluminoso parque de viviendas que tiene como destino preferente el uso permanente por población urbana que va instalando aquí su domicilio. Pero también acoge nuevas actividades económicas con la implantación de instalaciones industriales y, sobre todo, de dotaciones y equipamientos de servicios públicos y privados. Entre las consecuencias cabe destacar, además de una extraordinaria densificación del espacio edificado y de un significativo crecimiento demográfico, la acusada diversificación socioprofesional de la población.

Por otro, los espacios rurales más alejados de las principales ciudades en los que las nuevas viviendas tienen una ocupación intermitente y estacional, para población urbana no residente. Aquí la difusión urbana progresa en forma de un proceso de rururbanización, o contraurbanización según la perspectiva utilizada, derivado de dinámicas de descentralización metropolitana de radio más amplio (MAS, 1999). Por ello el crecimiento demográfico es más modesto, aunque la densificación edificatoria sea, en ocasiones, muy intensa. Así mismo, la diversificación socioprofesional de su población es menor y la actividad agraria continúa teniendo bastante peso.

Como ejemplo de esta segunda situación es obligado destacar el caso de los espacios del litoral oriental de la región en los que la proliferación de las actividades de ocio y turismo se enmarcan más en un proceso de descongestión urbana que en el de una verdadera estrategia de desarrollo rural, como una forma de colonización del espacio rural por funciones urbanas vinculadas al esparcimiento de la población del área metropolitana bilbaína en la que este espacio empieza a integrarse, en algunos casos, y cada vez en mayor medida, como área periurbana.

Sin embargo, por sus rasgos ambientales (situación en un litoral de alta calidad ecológica y gran atractivo paisajístico), por su proximidad a las mayores ciudades de Cantabria y a un área metropolitana extrarregional de gran dimensión y por la reciente mejora de la accesibilidad desde esa aglomeración, algunas áreas rurales cántabras están experimentando ambas formas de urbanización a la vez, lo que ha redundado en que la urbanización del espacio rural adquiera aquí mayor amplitud y profundidad al ser utilizado como área periurbana, de residencia permanente y de residencia secundaria de habitantes de las propias ciudades cántabras y del País Vasco, y como espacio turístico para habitantes de espacios urbanos más alejados. Todo ello está facilitando la formación en el litoral de Cantabria de un extenso complejo rururbano, residencial, productivo y turístico, que comporta un alto riesgo puesto que está empezando a originar importantes impactos negativos, tanto ambientales y paisajísticos como sociales y económicos. 


\section{BIBLIOGRAFÍA}

- AtKInson, R. y Moon, G. (1997): «The City Challenge Initiative: An Overview And Preliminary Assessement» en Regional Studies, vol. 31, nº 3, pp. 211220.

- BAUER, G. y ROUX, J-M. (1976): La rurbanisation ou la ville éparpillée. París, Ed. du Seuil.

- BREHENY, M. (1995): «Counterurbanization and Sustainable Urban Forms» en BrotchiE, J. (Ed.): Cities in Competition. Productive and Sustainable Cities for the $21^{\text {st }}$ Century. Melbourne, Longman Australia.

- CHESHIRE, P. (1995): «A new phase of urban development in Western Europe? The evidence for the 1980s» en Urban Studies, vol. 32, n ${ }^{\circ}$ 7, pp. 10451063.

- DELGAdO ViÑAS, C. (1997): «Dinamismo y atonía en el litoral de Cantabria» en Dinámica Litoral-Interior. Actas del XV Congreso de Geógrafos Españoles. Santiago de Compostela, Universidad de Santiago de Compostela/AGE, vol. II, pp. 903-911.

- DELGADO VIÑAS, C.: «Mutaciones económicas y funcionales de las pequeñas ciudades y villas de Cantabria» en Actas del IV Coloquio de Geografia Urbana "Ciudad y Turismo", en prensa.

- DELGADO ViÑAS, C.y GARCÍA MERINO, L.V. (1995): «Procesos y formas de crecimiento recientes en las ciudades del norte de España» en Cambios Regionales a finales del siglo XX. Actas del XIV Congreso Nacional de Geografía. Salamanca, Universidad de Salamanca/AGE, pp. 377-380.

- DEMATTEIS, G. (1998): «Suburbanización y periurbanización. Ciudades anglosajojas y ciudades latinas» en MonCLUS, F.J. (Ed.): La ciudad dispersa. Suburbanización y nuevas periferias. Barcelona, Centre de Cultura Contemporània de Barcelona, pp. 17-33.

- DupuY, G. (1995): Les Territoires de l'automobile. París, AnthroposEconomica.

- GARCÍA MERINO, L.V. (1996): «Redes urbanas y articulación del territorio en el Norte de España. Problemas y posibilidades de Cantabria» en Cámara Cantabria, $\mathrm{n}^{\circ} 43$, pp. 6-15, y no 45 , pp. 6-17.

- Hall, P. (1997): «The Future of the Metropolis and Its Form» en Regional Studies, vol. 31, $\mathrm{n}^{\mathrm{o}} 3$, pp. 211-220.

- HARVEY, D. (1996): «Cities or Urbanization?» en City. Analisis of Urban Trends, Culture, Theory, Policy, Action, no 1-2, pp. 38.

- INDOVINA, F.(Ed.) (1990): La città diffusa. Venecia, DAEST.

- JAILLET, M. Ch. y JALABERT, G. (1982): «La production de l'espace urbain périphérique» en Revue Géographique des Pyrenées et du Sud-Ouest, pp. 7-26.

- JALABERT, G. (1986): «Production d'espace et croissance périphérique des villes» en Estudios sobre Espacios Urbanos. Madrid, IEAL, pp. 451-458.

- LONGO, G. (1992): «La città sconfinata» en La città sostenibile. Roma, Ed. Delle Autonomie, pp. 90-93.

- MAS HERNÁNDEZ, R. (1999): «Periferias urbanas y nuevas formas espaciales» en La Ciudad: tamaño y crecimiento. Málaga, Departamento de Geografía de 
la Universidad de Málaga/AGE., pp. 201-233.

- NAREDO, J.M. (1994): «El funcionamiento de las ciudades y su incidencia en el territorio» en Ciudad y Territorio, $\mathrm{n}^{\circ}$ 100-101, pp. 233-249.

- NEL LO, O. (1998): «Los confines de la ciudad sin confines. Estructura urbana y límites administrativos» en MONCLUS, F.J. (Ed.): La ciudad dispersa. Suburbanización y nuevas periferias. Barcelona, Centre de Cultura Contemporània de Barcelona, pp. 35-57.

- RODRÍGUEZ GONZÁLEZ, R. (1997): La urbanización del espacio rural en Galicia. Barcelona.

- SERNINI, M. (1996): «Città senza confine» en Terre sconfinate. Città, limiti, localismo. Milán, Franco Angeli, pp. 23-85.

RESUMEN: Este artículo examina los intensos cambios que están teniendo lugar en algunos espacios rurales de Cantabria desde mediados de los años ochenta en relación con los procesos de difusión de los fenómenos urbanos. El estudio se apoya en el análisis de tres aspectos significativos: la evolución demográfica, el crecimiento del parque de viviendas y la implantación de nuevas actividades económicas. A través de estos tres indicadores resulta evidente que, entre los espacios urbanos densos y los rurales profundos, se está formando un espacio híbrido en el que la urbanización avanza a partir de la atribución a los espacios rurales de funciones hasta ahora esencialmente urbanas. El proceso está originando la formación de un extenso complejo rururbano que comporta un elevado nivel de riesgo de efectos ambientales y sociales negativos.

PALABRAS CLAVE: Difusión urbana, rururbanización, área periurbana, parque inmobiliario residencial, diversificación productiva y laboral.

ABSTRACT: This paper investigates the intense changes which many rural areas of Cantabria are happening in the decades of the very recent past; these changes are connected with the spread's processes of urban phenomena over the countryside. The research is based on analysis of three significant questions: the population's growth, the housing development and the location of new business. By means of all these three indicators it becomes apparent that a mixed area is growing between dense urban and deep rural areas. The urbanization process makes good progress here through the ascription to rural areas of especially urban functions until now. The process is leading to setting up on the Cantabrian coast of a large rural-urban fringe which involves a high danger of having environmental and social destructive effects.

KEY WORDS: Urban spread, counterurbanization, rural-urban fringes, productive and labour diversification, housing estate.

RÉSUMÉ: Cet article examine les substantielles mutations qui ont lieu depuis le milieu des années 1980 dans quelques espaces ruraux de la Cantabrie; ce sont des changements liés à la diffusion des phénomènes urbains sur le territoire. L'étude s'appuie sur l'analyse de trois aspects expressifs: l'évolution démographique, l'accroissement du parc de logements et l'implantation de nouvelles activités économiques. À travers ces trois indicateurs, il devient clair que, parmi les espaces urbains denses et les espaces ruraux profonds, se développe un espace hybride où l'urbanisation progresse à partir de l'attribution aux espaces ruraux de fonctions qui ont été essentiellement urbaines jusqu'à présent. Ce processus est en train de donner lieu à la formation d'une surface rurbaine 
complexe et étendue qui comporte un haut niveau de risque d'impacts environnementaux et sociaux négatifs.

MOTS-CLÉS: Diffusion urbaine, rurbanisation, espace urbain périphérique, parc immobilier résidentiel, diversification productive et du travail. 